\title{
Optimal control of a Fuel cell/Wind/PV/Grid hybrid system with thermal heat pump load
}

\author{
Sam Sichilalu ${ }^{\mathrm{a}, *}$, Henerica Tazvinga ${ }^{\mathrm{b}}$, Xiaohua Xia ${ }^{\mathrm{c}}$, \\ ${ }^{a}$ Department of Electrical and Electronic Engineering, University of Zambia, Zambia \\ ${ }^{b}$ Council of Scientific Industrial Research (CSIR) South Africa \\ ${ }^{c}$ Centre of New Energy Systems, Department of Electrical, Electronic and Computer Engineering, University of Pretoria, Pretoria \\ 0002, South Africa
}

\begin{abstract}
This paper presents an optimal energy management strategy for a grid tied photovoltaic-wind-fuel cell hybrid power supply system. The hybrid systems meets the load demand consisting of an electrical load and a heat pump water heater supplying thermal load. The objective is to minimize energy cost and maximize fuel cell output, taking into account the time-of-use electricity tariff. The optimal control problem is solved using a mixed integer linear program with the supply switch to the heat pump water heater and the power from the grid, power to/from inverter, power to electrolyzer and from fuel cell the control variables. The hot water temperature inside the water storage tank and the hydrogen in the storage tank are the state variables. The performance of the proposed control strategy is tested by simulating different operating scenarios: with and without renewable energy feed-in, and the results confirm the effectiveness of the proposed control strategy, as it increases the supply reliability of the system.
\end{abstract}

Keywords: Fuel cell; Heat pump water heater; Optimal control; dispatch strategy; Wind generator; Photovoltaics; Electrolyzer; Energy Feed-in.

\footnotetext{
${ }^{*}$ Corresponding author. Tel. +27 12420 6767; Fax +27 123625000.

Email address: Sam.Sichilalu@up.ac.za ; sichgroup@yahoo.com (Sam Sichilalu )
} 


\begin{tabular}{|c|c|}
\hline Nomenclature & \\
\hline$P_{w, t}$ & wind generator power output $(k W)$ \\
\hline$P_{p v, t}$ & photovoltaic power output $(\mathrm{kW})$ \\
\hline$P_{g, t}$ & grid power $(k W)$ \\
\hline$P_{h p, t}$ & heat pump water heater rated power $(k W)$ \\
\hline$P_{R E-I N, t}$ & direct renewable power supply $(k W)$ \\
\hline$P_{e l, t}$ & power supply to the electrolyzer $(\mathrm{kW})$ \\
\hline$P_{H 2, t}$ & eletrolyzer hydrogen power output $(k W)$ \\
\hline$H_{2, t}$ & stored hydrogen energy $(\mathrm{kWh})$ \\
\hline$P_{F C-I N, t}$ & fuel cell power output $(k W)$ \\
\hline$P_{\text {Load,t }}$ & domestic load $(k W)$ \\
\hline$P_{F C, t}$ & hydrogen power input to the fuel cell $(\mathrm{kW})$ \\
\hline $\mathrm{COP}$ & coefficient of performance \\
\hline$u_{t}$ & heat pump power supply switch control variable ( 0 or 1$)$ \\
\hline$T_{t}$ & hot water temperature inside the $\operatorname{tank}\left({ }^{\circ} \mathrm{C}\right)$ \\
\hline$T_{\text {low }}$ and $T_{u p}$ & lower and upper hot water temperature set points $\left({ }^{\circ} \mathrm{C}\right)$ \\
\hline$T_{a}$ & ambient temperature $\left({ }^{\circ} \mathrm{C}\right)$ \\
\hline$T_{o}$ & initial hot water temperature $\left({ }^{\circ} \mathrm{C}\right)$ \\
\hline$T_{i n, t}$ & inlet cold water temperature $\left({ }^{\circ} \mathrm{C}\right)$ \\
\hline$R$ & South African rands $(1 \mathrm{R}=0.074 \mathrm{USD}$ as of 22.09 .2015$)$ \\
\hline$p_{(t)}$ & time-of-use electricity price $(R / k W h)$ \\
\hline$N$ & total number of sampling intervals \\
\hline$t_{s}$ and $k$ & sampling time (hour) and $k^{\text {th }}$ sampling interval respectively \\
\hline$J$ & cost function \\
\hline$Q_{D}$ & total losses due to water demand \\
\hline$Q_{L}$ & total standby (convectional) losses \\
\hline$W_{D, t}$ & flow rate (litres/hour) \\
\hline qloss & conventional loss in $\left(\mathrm{W} / \mathrm{m}^{2}\right)$ \\
\hline$\Delta x$ & thickness of the insulation $(m)$ \\
\hline$h$ & surface heat transfer coefficient $\left(\mathrm{W} / \mathrm{m}^{2} K\right)$ \\
\hline$\kappa$ & thermal conductivity $(\mathrm{W} / \mathrm{m} \mathrm{K})$ \\
\hline$S_{\text {area }}$ & total surface area $\left(m^{2}\right)$ \\
\hline$c$ & specific heat capacity of water $\left(\mathrm{J} / \mathrm{kg}^{\circ} \mathrm{C}\right)$ \\
\hline$\varnothing$ & diameter $(m)$ \\
\hline$\dot{T}$ & derivative of temperature \\
\hline$L$ & mass of water inside the tank $(\mathrm{kg})$ \\
\hline$h_{r e f}$ & anemometer reference height $(m)$ \\
\hline$\varphi$ & ground surface friction coefficient \\
\hline$v_{h u b}$ & wind speed at the desired height $h_{h u b}$ \\
\hline$v_{\text {ref }}$ & wind speed at the reference height $h_{r e f}$ \\
\hline$V$ & wind speed at the hub height $(\mathrm{m} / \mathrm{s})$ \\
\hline$\chi$ & Weibull shape parameter \\
\hline$P_{r}$ & rated wind electrical power $(k W)$ \\
\hline$V_{\text {in }}$ & cut-in wind speed $(\mathrm{m} / \mathrm{s})$ \\
\hline$V_{r}$ & rated wind speed $(\mathrm{m} / \mathrm{s})$ \\
\hline$V_{\text {out }}$ & cut-off wind speed $(\mathrm{m} / \mathrm{s})$ \\
\hline MILP & Mixed integer linear program \\
\hline TOU & time-of-use electricity tariff \\
\hline Eskom & South African power utility company \\
\hline
\end{tabular}




\section{Introduction}

Rising costs, depletion and environmental concerns of fossil fuel-based energy resources have lead to significant research effort in renewable and cleaner energy resources. Globally, governments are adopting policies to promote the development and application of various renewable energy (RE) technologies for generating electricity. The main challenge associated with RE technologies such as solar and wind is their intermittent nature which impacts on their ability to provide $100 \%$ supply reliability. Combining these RE sources with battery storage and diesel generator systems has been shown in various studies to be cost effective[1, 2]. Currently there are limitations to the fraction of RE (wind and solar) that can be incorporated in the grid system due to their intermittency and base load considerations. With the latest developments pointing towards the feasibility of the hydrogen economy, solar and wind power fractions can be safely extended within the grid system by compensating their intermittency with an energy storage medium such as hydrogen. Interest in hydrogen is mainly driven by its ability to:reduce carbon dioxide emissions, thereby helping to mitigate climate change; improve local air quality; improve energy security by reducing energy imports; increasing energy supply options, reducing dependence on fossil fuels; and contribute to the introduction of advanced FC technologies with high efficiency.

Fuel Cells (FCs) are promising sources of electricity that are very efficient and environmentally friendly. Use of hydrogen fuel cells for power production is receiving a lot of research interest in many research communities with industrial applications in automobile industries and heat pumps [3]. FCs can serve as an emergency sources of energy in the event of long-term power outage and in stand alone applications. They are replacing the battery systems and are increasingly being widely used in distributed generation systems. Hydrogen, once produced and stored can generate power on demand. In order for PV and wind systems to meet demand completely, there is a need for backup systems such as diesel generators (DGs), hydrogen FCs and battery storage in a hybrid system. Hybrid energy systems present a resolution to the time correlation of intermittent RE sources [4, 5]. RE-based power systems are being deployed globally to provide autonomous power for various remote applications and also in grid-tied systems. Improvements in the performances of these systems for both grid and off-grid applications are on-going globally in many research communities [6].

Various energy management strategies have been proposed for different hybrid system configurations [7, 8, 9]. A standalone RE/FC hybrid system that uses least one RE sources and a Polymer Electrolyte Membrane (PEM) FC as backup source is analyzed in [10]. Frequency fluctuation analysis of a wind, DG and FC hybrid power system connected to a local utility point is done in [11] and the results show that the FC system can give better performance for stabilizing the frequency of the system in comparison to DGs. Electrochemical energy storage systems such as hydrogen systems can offer sufficient flexibility for operation in connection with stochastic generation from wind and PV and also the local energy storage can increase the exploitation of the energy source [8]. Usage of hydrogen as a storage medium for variable energy sources is a promising alternative in the long run, since it can be used as a clean fuel in the transport sector and for power production in stationary FCs [8, 10].

It is important to note that energy consumption in buildings especially in developed countries accounts for close to $42 \%$ of global energy production and $60.51 \%$ of this energy is used for space heating while $23.60 \%$ goes for water heating at domestic level [12, 13, 14]. Therefore, only energy-efficient equipment like heat pump water heaters (HPWH) should be used to produce the much needed thermal energy. The employing of HPWHs in demand side management(DSM) yields more benefit than its counterpart cylinder hot water heaters owing to its coefficient of performance (COP). Alot of success in optimal design and control of HPWHs in the last decades has increased their application even at domestic building levels [15]. Though, few challenges exist in providing the hot water at short time interval and the initial cost [16, 17]. Integration of such equipment with REs is the main challenge [18, 19, 20].

In most of the work done by various researchers, DGs with battery storage or grid are the common backup systems in RE-based hybrid systems and evaluation of performance index on life cycle cost analysis [21], [22], [23], [24]. While most of these above have either expensive fuel running cost or battery fumes. This work's novelty is in the proposed first ever model on optimal control strategy of a hybrid fuel cell system 
with an energy-efficient heat pump thermal load. The FC serves as an emergency source of energy together with the grid. Excess RE energy is used in the electrolysis of water to produce hydrogen and an optimally controlled HPWH is incorporated to cater for the thermal load. The main focus is to promote use of clean energy sources to meet the load and also to achieve savings in revenue by employing an energy efficient HPWH under a Time of Use (TOU) tariff as well this model presents a practical fuel cell feed-in optimal strategy. As well the model presents a $24 \mathrm{~h}$ simulations that gives a quick comprehensive understanding of the daily energy usage pattern and its implications. Often at times, customers rarely change their energy usage behavior mainly because they do not depict the hourly energy usage/bill collation from the accumulative monthly power utility bill.

This paper is structured as follows: Sections 2 and 3 present the mathematical model formulation and Section 4 the simulation results and discussion. The last part, Section 5 , is the conclusion.

\section{Mathematical model formulation}

\subsection{Schematic model layout}

The schematic layout is shown in Figure 1. The photovoltaic modules $P_{p v, t}$ and wind generator $P_{w, t}$ feeds through their respective inverters into the direct current (DC) bus. The DC bus then supplies through $P_{R E-I N, t}$ to the loads and the other $P_{e l, t}$ to the fuel cell's electrolyzer for the generation of hydrogen. The generated hydrogen power $P_{H 2, t}$ is stored in the hydrogen storage tank $H_{2, t}$ which later makes available this hydrogen through $P_{F C, t}$ to the fuel cell. The fuel cell output is rectified and feeds into grid alternating current (AC) bus through $P_{F C-I N, t}$ where the loads are connected.

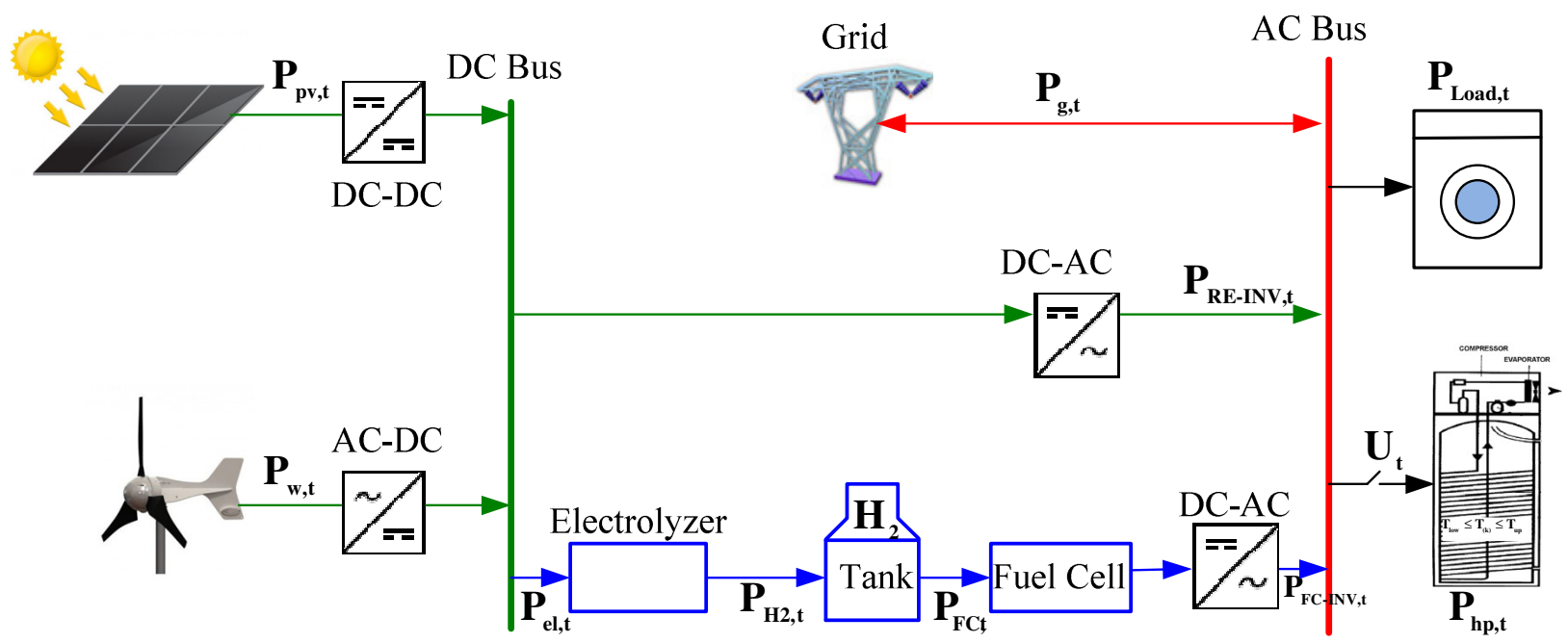

Figure 1: Schematic layout of a renewable energy-grid integrated model

The grid $P_{g, t}$ power supplies direct into the load AC bus with a possibility of REs feed-in. The domestic load $P_{\text {Load,t }}$ represent all other loads in the building apart from the thermal loads. The thermal load considered in this model is the heat pump water heater because of its high energy-efficiency. The heat pump $P_{h p, t}$ works at full load at its rated power whenever its in operation, controlled by switch $u_{t}$. The control variables are the $P_{R E-I N, t}, P_{e l, t}, P_{H 2, t}, P_{F C, t}, P_{F C-I N, t}, P_{g, t}$ and switch $u_{t}$. The state of hydrogen energy in the tank $H_{2, t}$ and the heat pump's hot water temperature $T_{t}$ are the two state variables.

\subsection{Sub-models}

\subsubsection{Heat pump water heater}

The heat pump model is developed according to [20, 25], with a fixed power demand $P_{h p}$ rating, operating at full capacity. The hot water temperature distribution inside the tank is treated as uniform. For modeling simplicity, the energy losses in the evaporator, refrigerant and compressor are neglected. The 
COP depicts the thermal equipment efficiency and is assumed to be constant taken from the case study, though in practice it varies dependent on input values. In this model, only energy losses due to hot water demand $Q_{D, t}$ and convectional (standby) loss $Q_{L, t}$ are modeled.

The standby losses, $Q_{L, t}$, represents power losses as a result of casing material surface conduction. The per second convention loss $q_{\text {loss }}$ in $W / \mathrm{m}^{2}$, according to [26], is given in equation [1],

$$
q_{\text {loss }}\left(T_{t}, T_{a}\right)=\frac{T_{t}-T_{a}}{\frac{\Delta x}{\kappa}+\frac{1}{h}}
$$

where $\Delta x$ and $\kappa$ are the insulation thickness and thermal conductivity coefficients respectively, $h$ is the surface heat transfer coefficient of the tank and $T_{t}, T_{a}$ are the hot water and ambient temperature respectively. A given tank surface area $S_{\text {area }}$, has a total standby losses of:

$$
Q_{L}\left(T_{t}, T_{a}\right)=q_{\text {loss }} S_{\text {area }} .
$$

The other loss is is due to the hot water demand $Q_{D, t}$, allowing inlet cold water. Consequently, every time demand occurs $T_{t}$ drops and inlet of cold water proportionally flows into the tank keeping a constant volume. Losses due to the hot water demand is given [27, 28]:

$$
Q_{D, t}=c W_{D, t}\left(T_{t}-T_{i n}\right),
$$

where $c=4180 \mathrm{~J} / \mathrm{kg} /{ }^{\circ} \mathrm{C}$ is the specific heat capacity of water. $T_{i n}$ is the municipal inlet water temperature whereas $W_{D, t}$ is the hot water demand flow rate in litres/hour.

The HPWH thermal output requirements and its corresponding electrical power input is [29, 27]:

$$
P_{h p, t}=\frac{Q_{D, t}+Q_{L, t}}{C O P} .
$$

The power balance is a dynamic equation. Let $Q_{H, t}$ be the total HPWH heat output kilowatts and $L$ the water mass (tank capacity) in kilograms. Then the power balance becomes a first derivative differential function given in equation (5) [30].

$$
\begin{gathered}
c L \dot{T}_{t}=Q_{H, t}-Q_{L, t}-Q_{D, t}, \\
Q_{H, t}=P_{h p} C O P u_{t} .
\end{gathered}
$$

By substituting equation (1) to (4) into equation (5), one gets

$$
\dot{T}_{t}=\frac{P_{h p} C O P u_{t}-S_{\text {area }}\left(\frac{T_{t}-T_{a}}{\frac{\Delta x}{k}+\frac{1}{h}}\right)-c W_{D, t}\left(T_{t}-T_{i n, t}\right)}{c L},
$$

denoting:

$$
\begin{gathered}
\alpha_{t}=\frac{S_{\text {area }}}{c L\left(\frac{\Delta x}{\kappa}+\frac{1}{h}\right)}+\frac{W_{D, t}}{L}, \\
\beta=\frac{P_{h p} C O P}{c L}, \\
\gamma_{t}=\frac{S_{\text {area }} T_{a}}{c L\left(\frac{\Delta x}{\kappa}+\frac{1}{h}\right)}+\frac{W_{D, t} T_{i n, t}}{L},
\end{gathered}
$$

then equation (7) becomes:

$$
\dot{T}_{t}=-\alpha_{t} T_{t}+\beta u_{t}+\gamma_{t}
$$




\subsubsection{Wind generator}

The power output of wind a turbine at a given site depends on wind velocity at hub height and turbine speed characteristics. As the standard height or reference for wind speed measurements for wind resource assessment is $10 \mathrm{~m}$ above the effective ground level, there is a need to determine the wind speed at hub height. This is important because it is the wind speed seen by the rotor of the wind turbine (hub height wind speed) that determines the actual power radiated by a particular turbine. The most common expression used for this purpose is the power-law equation, expressed as [31, 32, 9, 33]:

$$
v_{\text {hub }}=v_{\text {ref }} \cdot\left(\frac{h_{h u b}}{h_{\text {ref }}}\right)^{\varphi}
$$

where $v_{h u b}$ is the wind speed at the desired height $h_{h u b}, v_{r e f}$ is the wind speed at the reference height $h_{r e f}$ and $\varphi$ is the power law exponent, which represents the ground surface friction coefficient. The exponent is a function of height, time of day, season, nature of the terrain, wind speed, and temperature. It is low for smooth terrains, high for rough terrains and the values for typical classes are given in [32]. The coefficient ranges from $\frac{1}{7}$ to $\frac{1}{4}$. $\frac{1}{7}$ is used in this work, which is typical for open land. The $v_{h u b}$ obtained is then used in the wind power equation. The power output of a wind turbine thus depends on the wind speed pattern at the specific location, air density, rotor swept area and energy conversion efficiency from wind to electrical energy. Various models are used to simulate the wind turbine power output [34, 32].

The hub height velocity is used in the output power model to calculate the power generated by the wind turbine generator. The models used to describe the performance of WGs are different since different WGs have different power output performance curves. Various authors have developed different models for calculating the power output by making various assumptions and assuming that the turbine power curve has a linear, quadratic or cubic form [35, 36]. The general expression used is as follows:

$$
P_{w}= \begin{cases}P_{r} \frac{V^{\chi}-V_{\text {in }}^{\chi}}{V_{r}^{\chi}-V_{\text {in }}^{\chi},}, & \left(V_{\text {in }} \leq V \leq V_{r}\right) \\ P_{r}, & \left(V_{r} \leq V \leq V_{\text {out }}\right) \\ 0, & \left(0 \leq V_{\text {in }} \text { and } V \leq V_{\text {out }}\right)\end{cases}
$$

where $V$ is the wind speed at the hub height, $\chi$ is the Weibull shape parameter taken as 2 in this paper, $P_{r}$ is the rated electrical power; $V_{\text {in }}$ is the cut-in wind speed; $V_{r}$ is the rated wind speed and $V_{\text {out }}$ is the cut-off wind speed. The wind model parameters are from the case study given in Table 2

\subsubsection{Hydrogen Fuel Cell}

The hydrogen storage system consists of an electrolyser and hydrogen storage tank. The input energy for the electrolyser is supplied by the RE sources during periods of excess production for hydrogen production by water electrolysis using the surplus electric energy generated by the RE units, and is stored in tank to be used by the FC during periods when the energy produced by the RE sources is not enough to meet the load. The storage tank is operated within the maximum and minimum levels of hydrogen storage and a minimum amount of hydrogen should remain in the tank to maintain a security limit. The electrolyser is connected directly to the hydrogen tank and power from the electrolyser to the tank, $P_{e l, t}$, is given by:

$$
P_{e l, t}=\eta_{e l} P_{H 2, t},
$$

where $P_{e l, t}$ is the renewable power input to the electrolyzer, $P_{H 2, t}$ is the hydrogen power output and $\eta_{e l}$ is the efficiency of the electrolyser and is assumed to be constant. The energy in hydrogen storage tank at any given time is expressed as:

$$
E_{s, t}=E_{s, t-1}+\left(P_{H 2, t}-\frac{1}{\eta_{s}} P_{F C, t}\right) \cdot \Delta_{t},
$$


in which, $\eta_{s}$ is the storage discharging efficiency taken as 95\% owing to leakages and pumping [37]. The following general expression thus applies to the storage dynamics:

$$
E_{S, t}=E_{S}(0)+\sum_{\tau=1}^{t} P_{H 2, \tau} \Delta_{t}-\frac{1}{\eta_{s}} \sum_{\tau=1}^{t} P_{F C, \tau} \Delta_{t},
$$

where $E_{s}(0)$ is considered as the initial SOC of the storage tank.

$P_{H 2, \tau}$ is the power accepted by the storage at time $t$, and $\frac{1}{\eta_{s}} \sum_{\tau=1}^{t} P_{F C, \tau}$ is the drawn from the storage at time $t$. The mass of hydrogen stored in the tank at any given time $t$ is given by:

$$
\operatorname{Mass}_{h, t}=\frac{E_{s, t}}{H H V_{h}},
$$

where $H H V_{h}$ is the higher heating value of hydrogen equal to $39.7 \mathrm{kWh} / \mathrm{kg}$ [38], [8]. The storage operates within maximum and minimum limits.

Fuel cell stacks produce direct current at a voltage that varies with the load. A switching power converter is used to match the voltage produced by the fuel cell to the needs of the application and to protect the fuel cell from over-current or under-voltage conditions. In this work the application requires alternating current, so the electricity is then processed through DC/AC inverter. FCs also produce thermal energy but this is not considered in this work. There are various types of FCs and in this work the proton exchange membrane (PEM) fuel cell considered owing to its reliable performance under variable supply and its availability in a wide range of capacities. The output power, $P_{F C-I N, t}$ is a function of the input power, $P_{F C, t}$, and efficiency $\eta_{F C}$ (assumed constant) of the FC given by:

$$
P_{F C-I N, t}=\eta_{F C} P_{F C, t} .
$$

The fuel cell output is restricted within:

$$
E^{\min } \leq E_{s, t} \leq E^{\max }
$$

\subsubsection{Photovoltaic power}

The PV power output profile $P_{p v}(t)$ is an input data, taken from the case study in our previous research [19, 5]. The PV power input data is given in Figure 4. The PV power generation is bounded by:

$$
0 \leq P_{p v, t} \leq P_{p v}^{\max }
$$

\subsubsection{Grid power}

The grid is capable of accepting and supplying power to the AC bus where the load are connected. The Time-of-use (TOU) electricity tariff (dynamic pricing) is an important control parameter in load shifting strategy. In South Africa the main power utility is called ESKOM. Due to high power deficit and aging infrastructure the dynamic pricing was introduced to level the load and discourage peak period power consumption. The pricing $p_{(t)}$ is model is: off-peak $\left(p_{o}\right)$, standard $\left(p_{s}\right)$ and peak $\left(p_{p}\right)$. The recent Eskom 11 megaflex active energy-TOU tariff is adopted in this model. The TOU tariff is:

$$
p_{(t)}= \begin{cases}p_{o}=0.3656 \mathrm{R} / \mathrm{kWh} & \text { if } t \in[0,7] \cup[23,24], \\ p_{s}=0.6733 \mathrm{R} / \mathrm{kWh} & \text { if } t \in[7,8] \cup[11,19] \cup[21,23], \\ p_{p}=2.2225 \mathrm{R} / \mathrm{kWh} & \text { if } t \in[8,11] \cup[19,21],\end{cases}
$$

${ }^{1}$ http://www.eskom.co.za/ 
where $R$ is the South African rand and $t$ is the time of day with $t=0, \ldots, 23$.

The feed-in tariff is regulated by the National Energy Regulator of South Africa (NERSA) $)^{2}$ NERSA, through the renewable energy purchasing agency, is the single buyer office (SBO) of Eskom, guaranteeing the renewable energy market. The prevailing PV feed-in tariff is $3.94 R / k W h$, whereas for wind it is $1.25 R / k W h$.

\subsection{6. $D C$ and $A C$ bus power balance}

The power balance at the $\mathrm{DC}$ bus is given as:

$$
P_{e l, t}+P_{R E-I N, t} / \eta_{i n}=P_{w, t} \eta_{w}+P_{p v, t} \eta_{p v}
$$

where $P_{e l, t}$ is the renewable power input to the electrolyzer and $P_{R E-I N, t}$ is the direct renewable energy power supply to the loads. $\eta_{i n}, \eta_{w}$ and $\eta_{p v}$ are the efficiency of the DC/AC, wind generator and PV inverters respectively.

The power balance at the $\mathrm{AC}$ load bus is given as:

$$
P_{g, t}+P_{R E-I N, t}+P_{F C-I N, t}=P_{\mathrm{Load}, t}+P_{h p, t} u_{t} .
$$

where $P_{g, t}$ is the grid power , and $P_{F C-I N, t}$ is the fuel cell power output. $P_{\text {Load }, t}$ and $P_{h p, t} u_{t}$ are the domestic load and heat pump demand respectively, whereas $u_{t}$ is the heat pump's power supply switch.

\section{Discrete formulation of the model}

\subsection{Hot water temperature model}

The water demand flow rate $W_{D, t}$ and the inlet water, $T_{i n, t}$, are functions of time taken from the case study. The general discrete formulation of equation (11) in terms of the $k$-th hot water temperature is given in equation (24):

$$
T_{k+1}=\left(1-t_{s} \alpha_{k}\right) T_{k}+t_{s} \beta u_{k}+t_{s} \gamma_{k} .
$$

Then, $T_{k+1}$ at each interval can be derived as:

$$
\begin{aligned}
T_{1}= & \left(1-t_{s} \alpha_{0}\right) T_{o}+t_{s} \beta u_{0}+t_{s} \gamma_{0}, \\
T_{2}= & {\left[\left(1-t_{s} \alpha_{1}\right)\left(1-t_{s} \alpha_{0}\right)\right] T_{o}+t_{s} \beta\left[\left(1-t_{s} \alpha_{1}\right) u_{0}+u_{1}\right]+\left[\left(1-t_{s} \alpha_{1}\right) t_{s} \gamma_{0}+t_{s} \gamma_{1}\right], } \\
T_{3}= & {\left[\left(1-t_{s} \alpha_{2}\right)\left(1-t_{s} \alpha_{1}\right)\left(1-t_{s} \alpha_{0}\right)\right] T_{o}+t_{s} \beta\left[\left(1-t_{s} \alpha_{2}\right)\left(1-t_{s} \alpha_{1}\right) u_{0}+\left(1-t_{s} \alpha_{2}\right) u_{1}+u_{2}\right] } \\
& +\left[\left(1-t_{s} \alpha_{2}\right)\left(1-t_{s} \alpha_{1}\right) t_{s} \gamma_{0}+\left(1-t_{s} \alpha_{2}\right) t_{s} \gamma_{1}+t_{s} \gamma_{2}\right], \\
& \vdots \\
T_{k+1}= & T_{o} \prod_{j=0}^{k}\left(1-t_{s} \alpha_{j}\right)+t_{s} \beta \sum_{j=0}^{k} u_{j} \prod_{i=j+1}^{k}\left(1-t_{s} \alpha_{i}\right)+\sum_{j=0}^{k} t_{s} \gamma_{j} \prod_{i=j+1}^{k}\left(1-t_{s} \alpha_{i}\right),
\end{aligned}
$$

where; $T_{o}$ and $T_{k}$ are the initial and $k$-th water temperatures inside the tank respectively. $t_{s}$ is the sampling time, whereas $u_{k}$ is the $k$-th switch status, which is either 1 or $0 . \alpha_{j}$ and $\gamma_{j}$ are functions of equation (8) and equation (10) respectively and $\beta$ represents a constant given equation (9). The acceptable hot water temperature set points are given by inequality $(26)$ :

$$
T_{\text {low }} \leq T_{k} \leq T_{\text {up }},
$$

where, $T_{l o w}$ and $T_{u p}$ are the lower and upper desired temperatures respectively.

\footnotetext{
${ }^{2}$ http://www.nersa.org.za/
} 


\subsection{Objective function}

The multi-objective function consists of energy $\operatorname{cost} w_{1} t_{s} \sum_{k=1}^{N} P_{g, k} p_{k}$ minimization and maximization of fuel cell usage $w_{2} t_{s} \sum_{k=1}^{N} P_{F C-I N, k}$ in discrete time with weighting factors $w_{1}$ and $w_{2}$. The objective function is normalized to level the sensitivity of the weighting factor by dividing the grid power variable with a 1000 units. The control horizon is $24 \mathrm{~h}$, with $t_{s}$ being the sampling time, and the sampling interval is $(1 \leq k \leq N)$ whereas $p_{k}$ is TOU tariff. $N$ is the final sampling point.

The objective function:

$$
J=\frac{1}{1000} w_{1} t_{s} \sum_{k=1}^{N} P_{g, k} p_{k}-w_{2} t_{s} \sum_{k=1}^{N} P_{F C-I N, k}
$$

subject to:

$$
\begin{aligned}
& T_{\text {low }} \leq T_{o} \prod_{j=0}^{k}\left(1-t_{s} \alpha_{j}\right)+t_{s} \beta \sum_{j=0}^{k} u_{j} \prod_{i=j+1}^{k}\left(1-t_{s} \alpha_{i}\right)+\sum_{j=0}^{k} t_{s} \gamma_{j} \prod_{i=j+1}^{k}\left(1-t_{s} \alpha_{i}\right) \leq T_{\text {up }} \text {, } \\
& P_{e l, k}+P_{R E-I N, k} / \eta_{i n}=P_{w, k} \eta_{w}+P_{p v, k} \eta_{p v} . \\
& P_{g, k}+P_{R E-I N, k}+P_{F C-I N, k}=P_{\text {Load }, k}+P_{h p, k} u_{k} . \\
& 0 \leq P_{p v, k} \leq P_{p v}^{\max } . \\
& P_{e l, k}=\eta_{e l} P_{H 2, k}, \\
& P_{F C-I N, k}=\eta_{F C} P_{F C, k} . \\
& E^{\min } \leq E_{s}(0)+\sum_{\tau=1}^{k} P_{H 2, \tau} t_{s}-\frac{1}{\eta_{s}} \sum_{\tau=1}^{k} P_{F C, \tau} t_{s} \leq E^{\max }, \\
& P_{w}= \begin{cases}P_{r} \frac{V^{\chi}-V_{\text {in }}^{\chi}}{V_{r}^{\chi}-V_{\text {in }}^{\chi},}, & \left(V_{\text {in }} \leq V \leq V_{r}\right) \\
P_{r}, & \left(V_{r} \leq V \leq V_{\text {out }}\right) \\
0, & \left(0 \leq V_{\text {in }} \text { and } V \leq V_{\text {out }}\right)\end{cases} \\
& u_{k} \in\{0,1\} \text {, }
\end{aligned}
$$

\subsection{Algorithm formulation}

The this optimal control problem is solved using using the OPTI toolbox in MATLAB.

\subsubsection{The objective function}

The objective function is to minimize the grid energy cost under the TOU tariff while maximizing fuel cell power output.

For grid energy cost minimization $J_{e}$ :

$$
\begin{gathered}
J_{e}=f^{T} \mathbf{X}=\left[0 \ldots 0_{N}, p_{1} \ldots p_{N}, 0 \ldots 0_{N}, 0 \ldots 0_{N}, 0 \ldots 0_{N}, 0 \ldots 0_{N}\right]_{1 \times 6 N} \times \\
\times\left[u_{1} \ldots u_{N}, P_{g, 1} \ldots P_{g, N}, P_{R E-I N, 1} \ldots P_{R E-I N, N}, P_{H 2,1} \ldots P_{H 2, N}, P_{F C-I N, 1} \ldots P_{F C-I N, N}, P_{F C, 1} \ldots P_{F C, N}\right]_{6 N \times 1}^{\prime},
\end{gathered}
$$


for fuel cell power output maximization $J_{F C}$ :

$$
\begin{gathered}
J_{F C}=f^{T} \mathbf{X}=\left[0 \ldots 0_{N}, 0 \ldots 0_{N}, 0 \ldots 0_{N}, 0 \ldots 0_{N}, 1 \ldots 1_{N}, 0 \ldots 0_{N}\right]_{1 \times 6 N} \times \\
\times\left[u_{1} \ldots u_{N}, P_{g, 1} \ldots P_{g, N}, P_{R E-I N, 1} \ldots P_{R E-I N, N}, P_{H 2,1} \ldots P_{H 2, N}, P_{F C-I N, 1} \ldots P_{F C-I N, N}, P_{F C, 1} \ldots P_{F C, N}\right]_{6 N \times 1}^{\prime},
\end{gathered}
$$

finally the multi-objective function is:

$$
\min J=t_{s} w_{1} \sum_{k=1}^{N} J_{e}-t_{s} w_{2} \sum_{k=1}^{N} J_{F C},
$$

subject to

$$
\begin{array}{r}
\mathbf{A X} \leq \mathbf{b} \text { (linear inequality constraint), } \\
\mathbf{A}_{\mathbf{e q}} \mathbf{X}=\mathbf{b}_{\mathbf{e q}} \text { (linear equality constraint) }
\end{array}
$$

The limits of the control variables are restricted between the lower $l b$ and upper $u b$ bounds, given in equation (41).

$$
l b^{T} \leq \mathbf{X} \leq u b^{T}
$$

\subsection{Case study}

The case study is done on a facility in Pretoria South Africa. This facility intend to be a positive-energy building, the installation of wind, PV and fuel cell is under way. The current control strategy with these equipment is PID and logical controller. The baseline situation at the facility is that grid power supplies all the loads. Therefore, this paper proposes an optimal control strategy to these RE equipment on this facility. The sampling time $t_{s}=30 \mathrm{~min}$, while $N=48$ and the control horizon is $24 \mathrm{~h}$.

Due to the difficulties of consolidated input data of this facility, the relatively similar data is adopted from [20]. The inlet cold water temperature and hot water demand is shown in Figure 2 ;

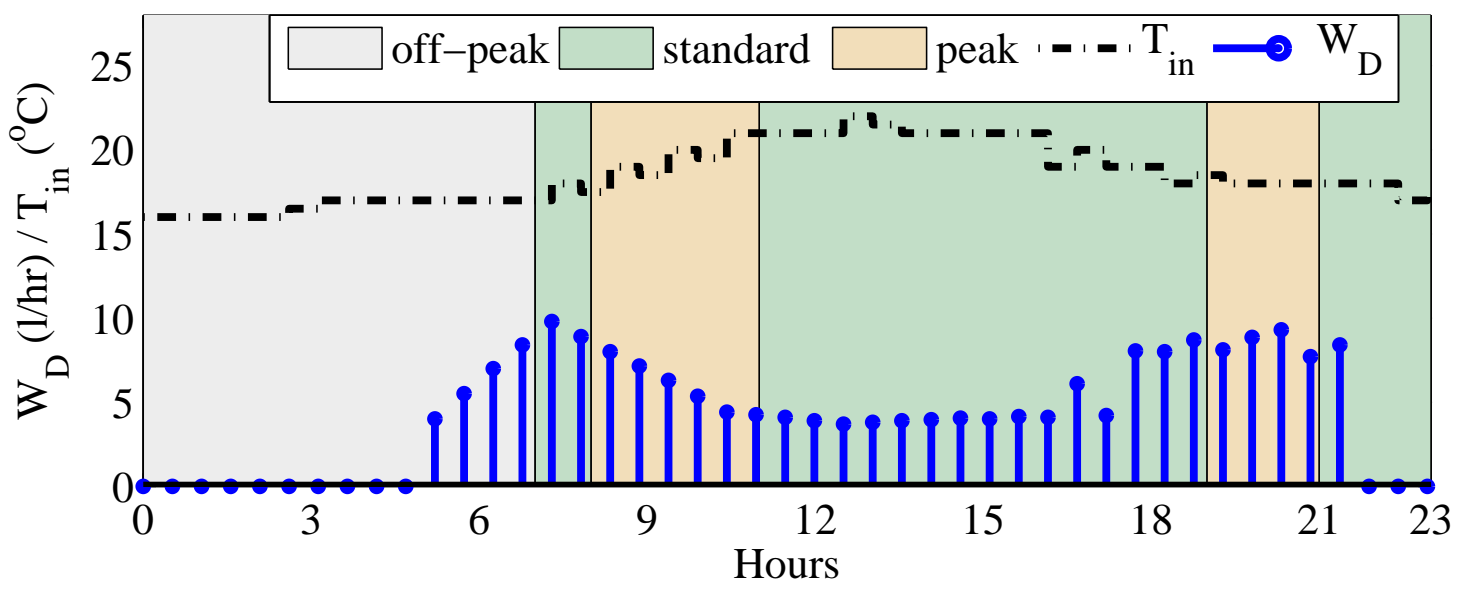

Figure 2: Flow rate 


\subsubsection{Heat pump water heater parameters}

The HPWH considered in this paper is Quantum solar heat pumf $3^{3}$ air source tank-wrapped heat exchanger (condenser), its parameters are shown in Table 1 .

Table 1: Heat pump parameters

\begin{tabular}{lccccccc}
\hline Power input $(k W)$ & COP & Storage capacity $(l)$ & Compressor $(c c)$ & Tank $(\mathrm{h} / \varnothing)(m)$ & $\Delta x(m)$ & $\kappa(W / m . K)$ & $h\left(W / m^{2} K\right)$ \\
\hline 7 & 3.8 & 270 & 39.0 & $1.41 \times 0.66$ & 0.035 & 0.055 & 6.3
\end{tabular}

The preferred hot water temperature is set to $55^{\circ} \mathrm{C} \leq T_{k} \leq 60^{\circ} \mathrm{C}$; the average country ambient temperature of $T_{a}=25^{\circ} \mathrm{C}$ is used. The initial water temperature in the tank is set to $T_{o}=57^{\circ} \mathrm{C}$. However, the above desirable temperature varies from one individual to another.

\subsubsection{Wind generator parameters}

The wind generator in the case study is Ruam Energy ${ }_{4}^{4}$ turbine with technical specifications given in Table 2. The parameters are given in Table 2:

Table 2: Wind generator parameters

\begin{tabular}{lccccccc}
\hline$P_{r}(k W)$ & $\varphi$ & $h_{\text {ref }}(m)$ & $h_{\text {hub }}(m)$ & $\chi$ & $V_{\text {in }}(\mathrm{m} / \mathrm{s})$ & $V_{r}(\mathrm{~m} / \mathrm{s})$ & $V_{\text {out }}(\mathrm{m} / \mathrm{s})$ \\
\hline 7 & $1 / 7$ & 10 & 30 & 2 & 2.0 & 11 & 50 \\
\hline
\end{tabular}

The wind turbine rated revolution per minute (RPM) is $280 R P M$ The hourly measured wind and hub height speed are shown in Figure 3 :

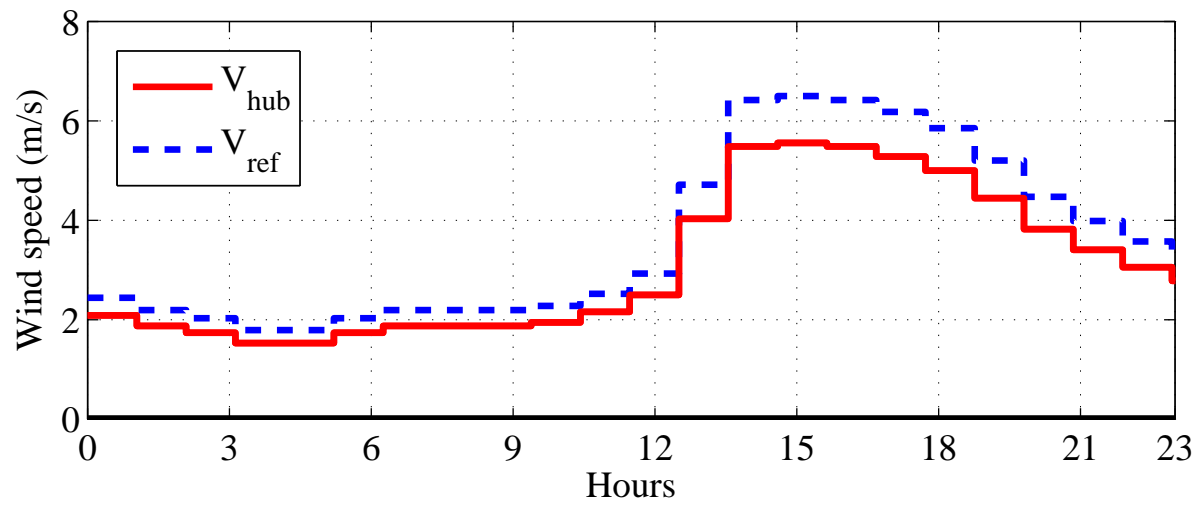

Figure 3: Hub height wind speed

\subsubsection{Photovoltaic power generation}

The PV power is input data in this model taken from our previous research [19, 5] on the data measured on an installed facility in South Africa. The power output $P_{p v}$ profile is given in Figure 4 far right.

\subsubsection{Inverter and fuel cell parameters}

The fuel cell under consideration is a stationary type with a wider application in commercial, industrial, and residential which can supplement the grid power supply. The electrolyzer efficiency is taken to be $\eta_{e l}=0.65$, hydrogen storage tank $\eta_{s}=0.95$ and overall fuel cell efficiency $\eta_{F C}=0.5$. The hydrogen tank energy storage capacity has a minimum $E^{\min }=0 \mathrm{kWh}$ and maximum $E^{\max }=25 \mathrm{kWh}$, the initial status of hydrogen energy is taken to be $E_{s}(0)=3 \mathrm{kWh}$. While all the inverters efficiency both DC/DC and AC/DC or vice versa is taken to be $\eta_{\text {in }}=0.98$.

\footnotetext{
${ }^{3}$ www.quantumecohotwater.com.au

${ }^{4}$ www.raumenergy.com
} 


\section{Simulation results and discussion}

The simulation are carried out to assess the feasibility and viability of implementing the proposed integrated fuel cell hybrid system. Two simulation scenarios are are analyzed: Case I without RE feed-in and Case II having RE energy feed-in to account for all the possible application of the proposed model.

\section{Case I}

\subsection{Optimal power control strategy of a fuel cell hybrid system}

The optimal power scheduling strategy of the fuel cell-grid- RE integrated system is shown in Figure 4 The weighting factors are set to $w_{1}=0.7$ and $w_{2}=0.3$, giving more weight on the minimization of grid energy. In Figure 4, the grid $P_{g}$ meets all domestic load $P_{\text {load }}$ and heat pump $P_{h p}$ from 00:00 till 07:00 end of the morning off-peak TOU period, due to non availability of wind energy $P_{w}$ and PV $P_{p v}$. There is no $P_{w}$ generation in this same period because of the wind velocities are below cut-in speed on this simulated day. Though the fuel cell has an initial status of energy $E_{s}(0)=3 \mathrm{kWh}$ (Figure 5), the OC opts avoids its usage because of poor energy conversion efficiency. The OC instead uses the off-peak TOU grid energy. The OC strategy changes at the TOU enters standard period at 07:00 the energy becomes slight expensive, the OC cuts grid supply and brings in the renewable power $P_{R E-I N}$ to sustain the domestic loads which is supplemented by the fuel cell. Unfortunately the heat pump switches on (in Figure 6) at 8:00 in the peak period, the available fuel cell and RE power cant meet the demand the grid comes in supply for an hour. During the afternoon standard TOU the fuel cell is not used to supplying power, the wind and PV with the grid meets the load. The cutting off of supply from the fuel cell can only be attributed its huge power loses in terms of efficiency whenever it operates.
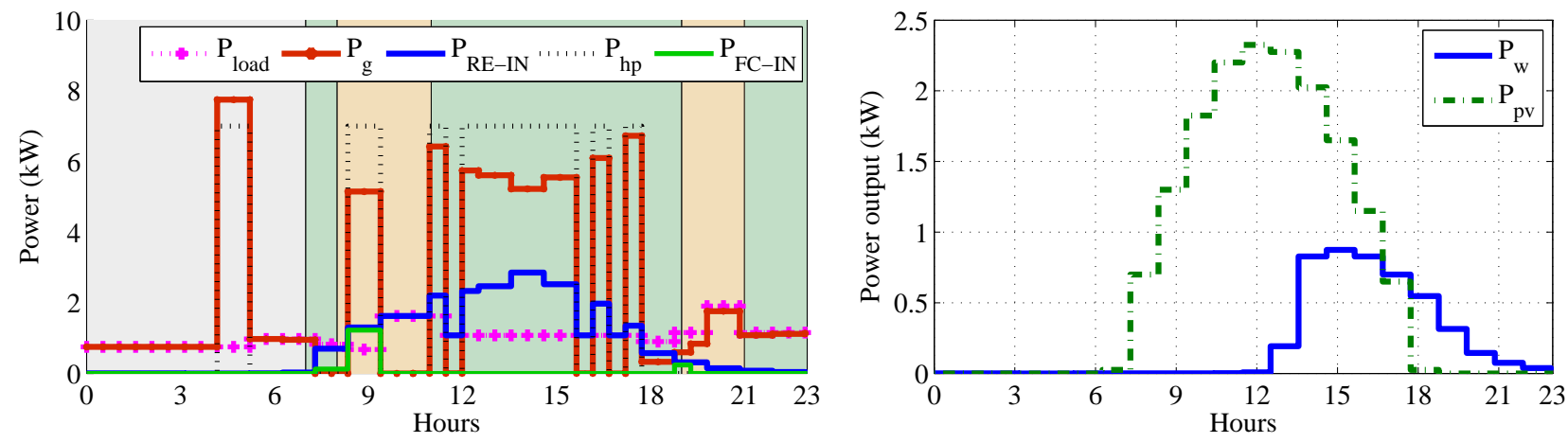

Figure 4: Optimal scheduling strategy and wind output

The optimal strategy in Figure 4, avoid as much as possible using peak TOU energy to save energy cost. The evening peak is mainly powered by the grid since $P_{p v}$ and the wind, in this period the PV power generation has finished. The hot water temperature set point bounds constraint Figure 6 are slightly stringent prompting the $\mathrm{OC}$ to increase the heat pump's switching $u_{k}$ frequency.

\subsection{Fuel cell scheduling strategy and hydrogen storage dynamics}

In Figure 5 an optimal fuel cell power dispatch is shown. The power source of the electrolyzer are the RE supply to generate hydrogen. The fuel cell power $P_{P F-I N}$ supply is off from 00:00 to 07:30, the loads are supplied by the grid during off-peak period. The stored hydrogen energy $H_{2}$ drops 07:30 due to the resumption of the fuel cell operation. $P_{F C-I N}$ supplies the load from 07:30 to 9:30 in the morning peak period. The stored hydrogen $\mathrm{H}_{2}$, sharply declines to minimum during this interval because the OC kept the electrolyzer switched off. There is no hydrogen generation is taking place till 10:00 when the heat pump demand reduced, the excess RE is then used for electrolyze water into hydrogen power $P_{H 2}$, the hydrogen mass builds in the tank. A stead increase in hydrogen storage is observed between 10:00 and 12:00, this is 
attributed to the low load demand. The OC again at 16:00 actuates the electrolyzer and hydrogen power $P_{H 2}$ production begins further increasing the stored hydrogen. During the evening peak, the fuel cell operates once again at this time only the fuel cell has enough power reserve since the RE production has dwindled.
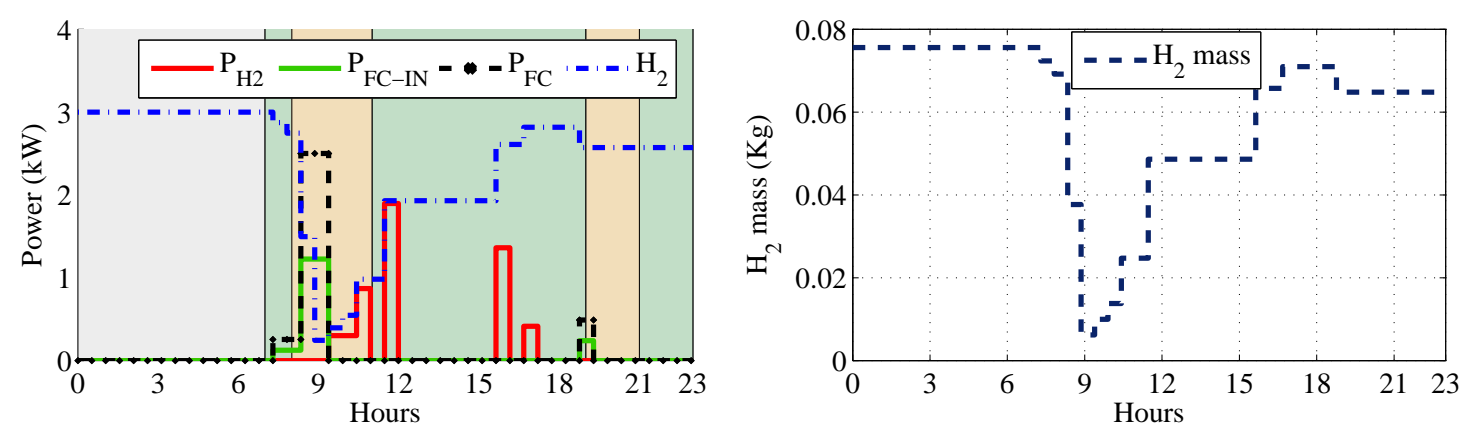

Figure 5: Fuel cell optimal control and hydrogen mass

The optimal control avoids operating the fuel cell at all times since a RE direct supply is more efficient. The OC just operates it as an energy storage device in peak period or when the RE is unavailable completely. However, depending on the desired effect the weighting factor can be adjusted to make sure the fuel once in operation replenish all the stored hydrogen. Because of a direct RE $P_{R E-I N}$ supply circuit to the loads that has minimal power loss on the inverter only, the OC gives high priority to this circuit than the fuel cell circuit that has output efficiency of $\eta_{F C}=0.5$. Therefore, the OC opts to keep its usage to bare minimum. In the same Figure 5, far right shows the accumulative hydrogen mass plotted according to equation (17). The pressure drop inside the tank limits the complete utilization of hydrogen, because of this, a lower and upper limit is given for a very storage tank.

\subsection{Heat pump thermal load switching control}

In this model, the domestic load is deterministic at each sampling interval. Only the thermal load is controllable, that is the switching status of the heat pump in this case. Switch $u_{k}$ is a variable dependent on the state of the hot water $T_{k}$ in the tank. It is assumed that at any sampling time the heat pump operates at its full rated power demand of $7 \mathrm{~kW}$. The lower and upper limits are set according to each individual's desired temperature range given in section 3.4. Figure 6 shows the optimal switching $u_{k}$ and the hot water state variable $T_{k}$ of the heat pump. The heat pump switch $u_{k}$ turns on around 04:00 for an hour and a corresponding rise in hot water temperature $T_{k}$ is observed. The water is preheated prior to the resumption of morning water demand (shown in Figure 2). From midnight to 04:30 when there is no hot water demand, a negligible drop in $T_{k}$ is seen owing to the best heat pump insulation level. However, the preheated water temperature sharply falls at the beginning of demand between 05:00 and 09:00. The OC switches on the heat pump again at 08:30 to heat the water that is almost hitting lower set-point. The inlet cold water is the major cause of the temperature drop inside the tank in addition to hot water demand. The OC operates the heat pump at 12:00 to 15:30 in readiness for the evening peak demand, thereby avoid operating it in the evening peak period and thereby making use of standard TOU that is relatively cheaper. 

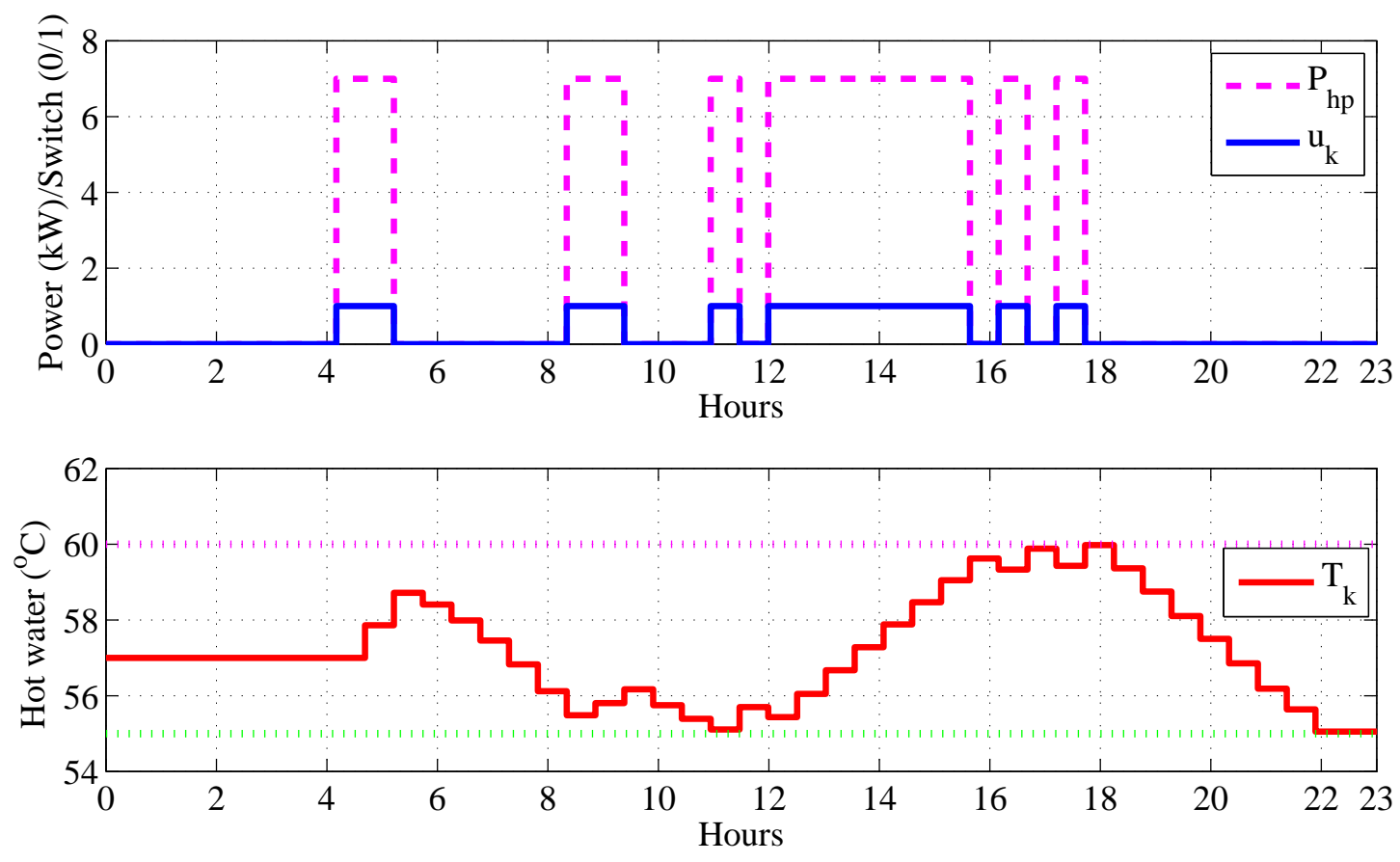

Figure 6: Optimal heat pump scheduling and hot water temperature

The heat pump water's temperature is highest between 17:00 and 18:30, enough to meet the evening demand and the rest of the night. The proposed models shows capacity to optimally predict, control and meets the state variable water constraint.

\section{Case II}

\subsection{Optimal feed-in power control strategy}

The notable major difference between the two operational scenarios in Figure 4 and Figure 7 is that the OC opts does not use the electrolyzer at all during case II. In Figure 7 the heat pump load scheduling strategy is rather spread throughout the whole control horizon. The REs feed-in takes place between 08:30 and 10:30 later on between 11:30 and 14:00 only during the periods when the heat pump is non operation. The OC stops the feed-in during peak load, because all the generated RE is used to supplement the grid power which is expensive to purchase.
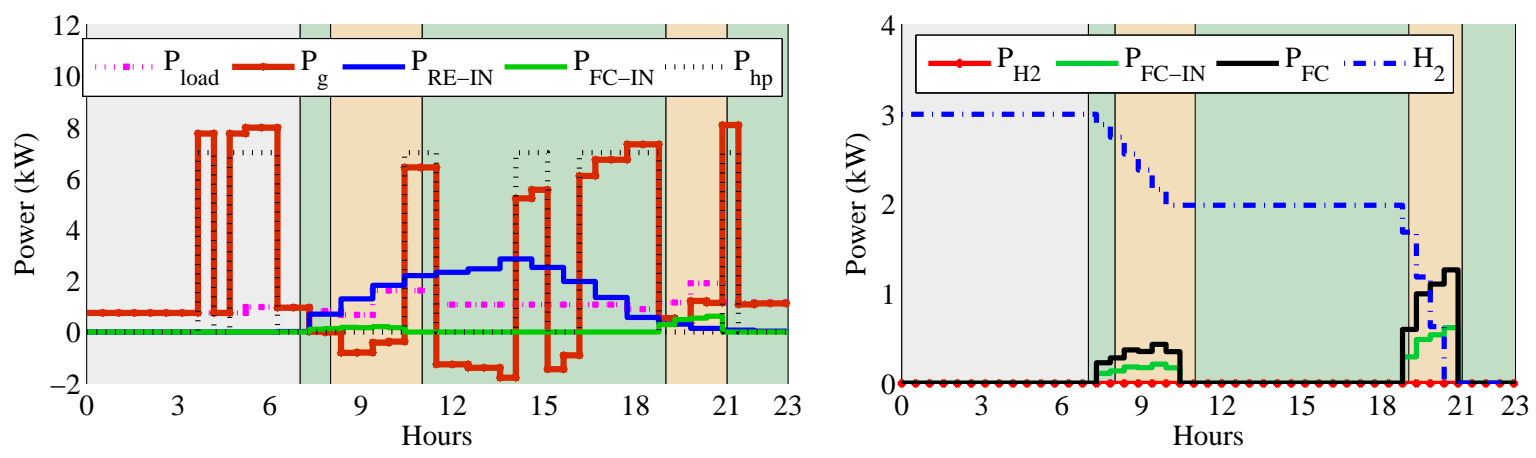

Figure 7: Optimal feed-in strategy

The fuel cell $P_{F C-I N}$ is used twice during peak period. This can be attributed to higher fuel cell system energy loss associated, therefore, the OC rather opts sell to the grid. The proposed model has shown greater capability in power control and can effectively improve the scheduling strategy of these systems mostly on programmable logic controllers. The optimal control technique maximizes the operational efficiency. 


\subsection{Baseline and optimal control savings}

The facility in the case study currently uses only the grid to sustain all the loads, here referred to as the baseline. The proposed intervention is the addition of wind, PV, fuel cell and optimal control referred as the optimal situation. Table 3 shows the baseline/current and after implementation of the model tabulating the predicted savings on a $24 \mathrm{~h}$ basis.

Table 3: Baseline and optimal energy/cost savings

\begin{tabular}{lccccc}
\hline $\begin{array}{l}\text { Baseline } \\
(\mathrm{kWh})\end{array}$ & $\begin{array}{c}\text { Baseline } \\
\text { cost }(\mathrm{R} / \text { day })\end{array}$ & $\begin{array}{c}\text { Optimal } \\
(\mathrm{kWh})\end{array}$ & $\begin{array}{c}\text { Optimal cost } \\
(\mathrm{R} / \text { day })\end{array}$ & $\begin{array}{c}\text { Energy saving } \\
(\%)\end{array}$ & $\begin{array}{c}\text { Cost } \\
\text { saving }(\%)\end{array}$ \\
\hline 74.00 & 66.08 & 53.52 & 43.69 & 27.68 & 33.8 \\
\hline
\end{tabular}

The energy saving is about $27.68 \%$ owing to the addition of the renewable sources coupled with optimal load shifting strategy. This analogous translates into reduced grid energy cost of $33.8 \%$. The proposed model has a potential on positive savings for this facility in the case study, provided the REs rides on optimal control strategy instead of the traditional logical controllers. Though this paper does not look into economic analysis and payback period, it could be interesting in the the future research to quantify these estimates. The proposed model opens door in integration and optimal control of fuel cell with other distributed renewable energy sources especially in developing countries experiencing power deficit(e.g., Zambia).

\section{Conclusions}

The proposed optimal control of an integrated fuel cell hybrid energy system with a thermal load meets all the operation constraints. The optimal is providing the required hot water demand and optimally scheduled the renewable energy system with fuel cell mainly used as back-up/storage energy sources. The model shows capability to be used for feed-in and load shifting in order to minimize grid energy cost, it avoids operating the thermal load in the peak TOU period. The proposed model can effectively improve the operational and system efficiency that results into minimization of energy losses. The engineering challenge facing RE and energy-efficient equipment integration has been solved in this paper especially on DSM. The traditional control methods such as programmable logic controller used in operation of such hybrid system can not effectively match the capability of the optimal control strategy in the current energy mix and electricity market environment. On the other hand, future research should apply model predictive control techniques if all the uncertainty nature of the input data and renewable energy generation are to be alleviated. However, this binary mixed integer optimal control model gives best controller optimal reference setting values that meets both the technical and operation constraints, and can be adopted for renewable energy hybrid supply and feed-in on commercial or domestic building.

\section{Acknowledgements}

The authors thanks the National Research Foundation (NRF) grant No. NRF SFH14080687344 South Africa, The University of Zambia, Council for Scientific and Industrial Research (CSIR) South Africa and the National Hub for Energy Efficiency and Demand Side Management (EEDSM) for financial and other support for this research.

\section{References}

[1] T. Hove, H. Tazvinga, A techno-economic model for optimising component sizing and energy dispatch strategy for pv-dieselbattery hybrid power systems, Journal of Energy in Southern Africa 23 (4) (2012) 18-28.

[2] R. Dufo-Lopez, J. L. Bernal-Agustin, J. M. Yusta-Loyo, J. Dominguez-Navarro, I. J. Ramirez-Rosado, J. Lujano, I. Aso, Multi-objective optimization minimizing cost and life cycle emissions of stand-alone pv-wind-diesel systems with batteries storage, Applied Energy 88 (11) (2011) 4033-4041. 
[3] M. Ellis, M. von Spakovsky, D. Nelson, Fuel cell systems: efficient, flexible energy conversion for the 21st century, Vol. 89, 2001, pp. 1808-1818. doi:10.1109/5.975914.

[4] M. Ranaboldo, B. Domenech, G. A. Reyes, L. Ferrer-Martí, R. P. Moreno, A. García-Villoria, Off-grid community electrification projects based on wind and solar energies: A case study in nicaragua, Solar Energy 117 (2015) 268-281.

[5] H. Tazvinga, X. Xia, J. Zhang, Minimum cost solution of photovoltaics-diesel-battery hybrid power systems for remote consumers, Solar Energy 96 (2013) 292-299.

[6] M. Bouzerdoum, A. Mellit, A. Massi Pavan, A hybrid model (sarima-svm) for short-term power forecasting of a small-scale grid-connected photovoltaic plant, Solar Energy 98 (2013) 226-235.

[7] A. Choudar, D. Boukhetala, S. Barkat, J.-M. Brucker, A local energy management of a hybrid pv-storage based distributed generation for microgrids, Energy Conversion and Management 90 (2015) 21-33.

[8] M. Korpås, A. T. Holen, Operation planning of hydrogen storage connected to wind power operating in a power market, Energy Conversion, IEEE Transactions on 21 (3) (2006) 742-749.

[9] H. Tazvinga, B. Zhu, X. Xia, Energy dispatch strategy for a photovoltaic-wind-diesel-battery hybrid power system, Solar Energy 108 (2014) 412-420.

[10] N. Bizon, M. Oproescu, M. Raceanu, Efficient energy control strategies for a standalone renewable/fuel cell hybrid power source, Energy Conversion and Management 90 (2015) 93-110.

[11] S. Singh, M. Singh, S. Chanana, S. Semwal, Frequency regulation of isolated hybrid wind/diesel, power generation with fuel cell system in: C. Kamalakannan, L. P. Suresh, S. S. Dash, B. K. Panigrahi (Eds.), Power Electronics and Renewable Energy Systems, Vol. 326 of Lecture Notes in Electrical Engineering, Springer India, 2015, pp. 853-862. URL http://dx.doi.org/10.1007/978-81-322-2119-7_83

[12] M. M. Rahman, M. Rasul, M. M. K. Khan, Energy conservation measures in an institutional building in sub-tropical climate in australia, Applied Energy 87 (10) (2010) 2994-3004.

[13] T. Chow, Y. Bai, K. Fong, Z. Lin, Analysis of a solar assisted heat pump system for indoor swimming pool water and space heating, Applied Energy 100 (2012) 309-317.

[14] X. Zhang, X. Zhao, J. Xu, X. Yu, Characterization of a solar photovoltaic/loop-heat-pipe heat pump water heating system, Applied Energy 102 (2013) 1229-1245.

[15] K. Chua, S. Chou, W. Yang, Advances in heat pump systems: A review, Applied Energy 87 (12) (2010) 3611-3624.

[16] C. Verhelst, D. Degrauwe, F. Logist, J. Van Impe, L. Helsen, Multi-objective optimal control of an air-to-water heat pump for residential heating, Building Simulation 5 (3) (2012) 281-291. doi:10.1007/s12273-012-0061-z

[17] P. Rousseau, G. Greyvenstein, Enhancing the impact of heat pump water heaters in the south african commercial sector, Energy 25 (1) (2000) 51-70.

[18] N. Roonprasang, P. Namprakai, N. Pratinthong, Experimental studies of a new solar water heater system using a solar water pump, Energy 33 (4) (2008) 639-646.

[19] S. M. Sichilalu, X. Xia, Optimal energy control of grid tied pv-diesel-battery hybrid system powering heat pump water heater, Solar Energy 115 (2015) 243-254.

[20] S. Sichilalu, T. Mathaba, X. Xia, Optimal control of a wind-pv-hybrid powered heat pump water heater, Applied Energy (2015)-doi:http://dx.doi.org/10.1016/j.apenergy.2015.10.072

[21] P. Rodatz, G. Paganelli, A. Sciarretta, L. Guzzella, Optimal power management of an experimental fuel cell/supercapacitorpowered hybrid vehicle, Control Engineering Practice 13 (1) (2005) 41-53.

[22] J. T. Pukrushpan, A. G. Stefanopoulou, H. Peng, Control of fuel cell power systems: principles, modeling, analysis and feedback design, Springer Science and Business Media, 2004.

[23] J. T. Pukrushpan, A. G. Stefanopoulou, H. Peng, Modeling and control for pem fuel cell stack system, in: American Control Conference, 2002. Proceedings of the 2002, Vol. 4, IEEE, 2002, pp. 3117-3122.

[24] C.-Y. Li, G.-P. Liu, Optimal fuzzy power control and management of fuel cell-battery hybrid vehicles, Journal of power sources 192 (2) (2009) 525-533.

[25] M. Kim, M. S. Kim, J. D. Chung, Transient thermal behavior of a water heater system driven by a heat pump, International journal of refrigeration 27 (4) (2004) 415-421.

[26] J. Zhang, X. Xia, Best switching time of hot water cylinder-switched optimal control approach, in: AFRICON 2007, IEEE, 2007, pp. 1-7.

[27] K. Khan, M. Rasul, M. M. K. Khan, Energy conservation in buildings: cogeneration and cogeneration coupled with thermal energy storage, Applied Energy 77 (1) (2004) 15-34.

[28] M. Gustafson, J. Baylor, G. Epstein, Direct water heater load control-estimating program effectiveness using an engineering model, Power Systems, IEEE Transactions on 8 (1) (1993) 137-143.

[29] J. Ji, G. Pei, T.-t. Chow, W. He, A. Zhang, J. Dong, H. Yi, Performance of multi-functional domestic heat-pump system, Applied Energy 80 (3) (2005) 307-326.

[30] P. Dolan, M. Nehrir, V. Gerez, Development of a monte carlo based aggregate model for residential electric water heater loads, Electric Power Systems Research 36 (1) (1996) 29-35.

[31] R. Belfkira, L. Zhang, G. Barakat, Optimal sizing study of hybrid wind/pv/diesel power generation unit, Solar Energy 85 (1) (2011) $100-110$.

[32] M. R. Patel, Wind and Solar Power Systems: Design, Analysis, and Operation, CRC Press, 2006, Boca Raton, FL.

[33] H. Li, Z. Chen, H. Polinder, Optimization of multibrid permanent-magnet wind generator systems, Energy Conversion, IEEE Transactions on 24 (1) (2009) 82-92. 
[34] S. Ashok, Optimised model for community-based hybrid energy system, Renewable energy 32 (7) (2007) 1155-1164.

[35] L. Lu, H. Yang, J. Burnett, Investigation on wind power potential on Hong Kong islands : An analysis of wind power and wind turbine characteristics, Renewable Energy 27 (1) (2002) 1-12.

[36] C. Bueno, J. Carta, Technical-economic analysis of wind-powered pumped hydrostorage systems. part i: model development, Solar Energy 78 (3) (2005) 382-395.

[37] C. Wallmark, P. Alvfors, Design of stationary pefc system configurations to meet heat and power demands, Journal of Power Sources 106 (1) (2002) 83-92.

[38] A. K. Kaviani, G. Riahy, S. Kouhsari, Optimal design of a reliable hydrogen-based stand-alone wind/pv generating system, considering component outages, Renewable Energy (2009) 2380-2390. 